\title{
Cerâmicas odontológicas: Uma revisão de literatura
}

\author{
Odontological ceramics: a review of literature \\ Cerámica odontológica: una revisa de literatura
}

José Milton de Aquino e Silva Neto ${ }^{1 *}$, Kassia Regina dos Santos Furtado ${ }^{1}$, Mariana Correia de Araújo Baumberger ${ }^{1}$, Isabel Karine Ferreira Duarte ${ }^{1}$, Arlette Murgado Trujillo ${ }^{1}$, Eliana Vilela Rocha Alves $^{1}$, Michelle Leão Bittencourt Brandão Medeiros ${ }^{1}$, Tayguara Cerqueira Cavalcanti ${ }^{1}$, Aleska Dias Vanderlei ${ }^{1}$, Bruno de Castro Figueiredo ${ }^{1}$, Ângela Líbia Chagas do Amaral ${ }^{1}$.

\section{RESUMO}

Objetivo: Auxiliar na escolha e indicação do material cerâmico de acordo com a situação clínica, esclarecendo as expectativas que podem ser geradas e minimizando assim as falhas decorrentes do mau uso e falhas na seleção do mesmo. Métodos: Foi realizado uma revisão de literatura, com abordagem descritiva e caráter informativo, onde o procedimento de elaboração se deu mediante buscas por literaturas cientificas, em bases de dados, tendo como descritores: A utilização da cerâmica dentária, porcelanato e prótese dentária. Resultados: Várias propriedades desejáveis nas cerâmicas quando utilizadas como substituto de dentes naturais como o coeficiente de expansão térmica semelhante ao dente, translucidez, estabilidade química, fluorescência, resistência à abrasão e à compressão, compatibilidade biológica, mimetização de esmalte e dentina, boa adaptação marginal e boa relação com os tecidos periodontais, fazem com que as mesmas tenham uma grande utilização clínica, contribuindo assim, para uma longevidade do tratamento restaurador. Considerações Finais: Para a seleção adequada da cerâmica o profissional deverá avaliar, de forma diferente, vários aspectos para assegurar uma maior longevidade e sucesso do tratamento restaurador visto que os sistemas cerâmicos têm evoluído bastante e os pré-requisitos necessários quanto às características e limitações para cada situação clínica são muitos.

Palavras-chave: Cerâmica, Porcelana dentária, Próteses e implantes.

\begin{abstract}
Objective: Assist in choosing and indicating the ceramic material according to the clinical situation, clarifying the expectations that can be generated and thus minimizing the failures resulting from misuse and selection failures. Methods: A descriptive and informative literature review was carried out, in which the elaboration procedure was performed by searching for scientific literature in databases, with the following descriptors: The use of dental ceramics, porcelain and dental prosthesis. Results: Several desirable properties in ceramics when used as a natural tooth replacement such as the coefficient of tooth-like thermal expansion, translucency, chemical stability, fluorescence, abrasion and compressive strength, biological compatibility, enamel and dentin mimicry, good marginal fit and good relationship with periodontal tissues, make them have a great clinical use, thus contributing to a longevity of restorative treatment. Final Considerations: For the proper selection of ceramics, the practitioner should evaluate differently, several aspects to ensure a longer longevity and success of restorative treatment since the ceramic systems have evolved a lot and the necessary prerequisites as to the characteristics and limitations for each clinical situation are many.
\end{abstract}

Key words: Ceramics, Dental porcelain, Prostheses and implants.

\footnotetext{
${ }^{1}$ Centro Universitário CESMAC (CESMAC), Maceió-Alagoas.

*E-mail: Milton_neto_166@hotmail.com
} 


\section{RESUMEN}

Objetivo: Ayude a elegir e indicar el material cerâmico de acuerdo con la situación clínica, aclarando las expectativas que se pueden generar y, por lo tanto, minimizando las fallas resultantes del mal uso y las fallas de selección. Métodos: Se realizó una revisión descriptiva e informativa de la literatura en la cual el procedimiento de elaboración se realizó mediante la búsqueda de literatura científica em bases de datos, con los seguientes descriptores: El uso de cerámica dental, porcelana y prótesis dental. Resultados: Varias propriedades deseables en cerámica cuando se usa como un reemplazo natural del diente, como el coeficiente de expansión térmica similar al diente, translucidez, estabilidad química, fluorescencia, abrasión y resistencia a la compresión, compatibilidad biológica, imitación de esmalte y dentina, buen ajuste marginal y buena relación con los tejidos periodontales, hacen que tengan un gran uso clínico, contribuyendo así a una longevidad del tratamiento restaurador. Consideraciones finales: Para la selección adecuada de la cerámica, el profesional debe evaluar de manera diferente varios aspectos para garantizar una mayor longevidad y el éxito del tratamiento restaurador, ya que los sistemas cerámicos han evolucionado mucho y los requisitos previos necesarios en cuanto a las características y limitaciones para cada situación clínica. son muchos.

Palabras clave: Cerámica, Porcelana dental, Prótesis e implantes.

\section{INTRODUÇÃO}

Apesar da longa história dos materiais cerâmicos, sua utilização rotineira para restaurar elementos dentais é um acontecimento que marca uma nova era na história da Odontologia estética, apresentando-se como uma excelente alternativa na reprodução e mimetização de esmalte e dentina (BISPO LB, 2015). O aumento da permanência dos dentes na cavidade bucal refletiu no crescimento do uso das cerâmicas, em casos que vão além da prótese total, protocolos, coroas e próteses fixas, bem como em onlays, inlays e facetas (KRISHNA JV, et al., 2009).

Várias propriedades são observadas nas cerâmicas, sendo elas: O coeficiente de expansão térmica semelhante ao dente, translucidez, estabilidade química, fluorescência, resistência à abrasão e à compressão, compatibilidade biológica, fazem com que elas tenham uma grande utilização clínica. Porém, um bom resultado estético depende também da integridade marginal, caracterização da superfície, anatomia e cor, além da compatibilidade final das cores quando comparadas aos dentes naturais (CALIXTO R e MASSING N, 2015).

As cerâmicas mimetizam a estrutura dental, permitindo uma boa adaptação marginal e relação com os tecidos periodontais, contribuindo assim, para a longevidade do tratamento restaurador (SHRIVASTAVA S, et al., 2014). Resistência flexural e tenacidade servem como indicadores para a escolha do material adequado para cada caso clínico, já que regiões posteriores e caninos, as quais recebem maior tensão, necessitam de cerâmicas que possuam altos valores dessas propriedades (GARCIA LFR, et al., 2011).

Durante a reabilitação do paciente, não se deve levar em consideração apenas o restabelecimento da estética e função das restaurações, mas também, da parte biológica (estabilidade do tecido gengival para integração da restauração), para que haja uma durabilidade das mesmas. Características do material, espessura da peça e quantidade de elementos reabilitados interferem na estabilidade de cor das cerâmicas, apesar destas sofrerem pouca ou nenhuma pigmentação intrínseca ou extrínseca (CALIXTO R e MASSING N, 2015).

Critérios concretos a respeito da durabilidade e longevidade de procedimentos como: laminados cerâmicos, fragmentos e coroas, são difíceis de serem conseguidos, uma vez que o sucesso depende da adaptação da peça, degradação marginal, presença de infiltrações e /ou cáries secundárias, material e técnica adesiva, tipo do agente cimentante utilizado, além da presença de instabilidades oclusais (MCLAREN EA e FIGUEIRA J, 2015). 
Escolher o material adequado diante da variedade de sistemas cerâmicos encontrados no mercado tornouse uma tarefa difícil, porque os pré-requisitos necessários quanto às características e limitações para cada situação clínica são muitos (MATTEI FP e ALEXANDRE MC, 2011). As cerâmicas para confecção de laminados devem apresentar propriedades distintas das cerâmicas utilizadas para confecção de uma barra de protocolo, daí a necessidade do profissional possuir conhecimento científico, além do conhecimento sobre os vários materiais disponíveis no mercado (composição e indicação), identificando limitações estabelecendo corretos diagnóstico, planejamento, preparos, protocolos restauradores para obter sucesso clínico (CALIXTO R e MASSING N, 2015).

Diante disso, este trabalho tem como objetivo, através de uma revisão de literatura, auxiliar na escolha e indicação do material cerâmico de acordo com a situação clínica, esclarecendo as expectativas que podem ser geradas na escolha do mesmo.

\section{METODOLOGIA}

Para o desenvolvimento deste trabalho foi realizada uma revisão de literatura, consultados textos em língua portuguesa e inglesa, sendo feita entre o período de novembro de 2017 a novembro de 2019, onde foram analisados artigos publicados em bases de dados eletrônicos LILACS (Literatura Latino Americana e do Caribe em Ciências da Saúde), MEDLINE (Literatura Internacional em Ciência da Saúde) e SCIELO (Scientific Electronic Library Online) e livros que estavam disponíveis nos acervos bibliográficos presentes na biblioteca central do Centro Universitário CESMAC (Centro de Ensino Superior de Maceió).

Foram consultados textos em língua portuguesa e inglesa, que se referiram a utilização da cerâmica na aplicação odontológica, tendo como critérios de exclusão os períodos de publicações, os artigos que não estavam na integra, ensaios não controlados, monografias e os artigos que não possuíam relevância com a temática, sendo selecionados os textos científicos que apresentavam na íntegra o real objetivo do trabalho, observando a importância do conhecimentos e das técnicas implantadas em cada cerâmica, visando o melhor procedimento para a obtenção de resultados satisfatórios e benéficos para o paciente, sendo selecionadas publicações científicas no período entre 2008 e 2019, com ênfase no intervalo entre 2014 e 2019, dispondo dos seguintes descritores: Utilização da cerâmica além da utilização em prótese total, coroas e próteses fixas, utilização onlays, inlays e facetas.

\section{RESULTADOS E DISCUSSÃO}

O conhecimento da biomecânica da estrutura do dente se faz necessário para a escolha do tipo de material restaurador pois é importante que além do aspecto estético, que esse material mimetize as propriedades biomecânicas do dente, já que o esmalte e a dentina sozinhos não seriam capazes de suportar o estresse gerado no dente durante sua função. Portanto, a dureza do esmalte protege a dentina de sua flexibilidade e vice-versa, gerando assim um equilíbrio biomecânico entre essas estruturas. A perda da estrutura do esmalte prejudica a rigidez coronária. (MAGNO P e BELSER U, 2012).

Baseado nas indicações e estética de cada cerâmica, o dentista deve saber a respeito dos cimentos e técnicas de cimentação para cada situação clínica, selecionar adequadamente os sistemas adesivos e cimentos resinosos, isolamento do campo operatório, estar atento às recomendações dos fabricantes, além de observar a espessura ideal da cerâmica, usar o substrato de maior módulo de elasticidade possível, observar força de adesão interface dente-cimento-cerâmica e devolver os contatos oclusais (HELVEY GA, 2014). As cerâmicas precisam ser classificadas de acordo com sua composição, método de processamento, resistência, temperatura de fusão, translucência, indicações clínicas, cimentação e sensibilidade de superfície (MCLAREN EA e FIGUEIRA J, 2015).

Quanto à composição podem ser vítreas (feldspátcas, reforçadas com: leucita, dissilicato de lítio ou silicato de lítio), infiltradas (alumina, alumina e magnésio, alumina e zircônia) e policristalinas. A quantidade de cristais na matriz vítrea influencia diretamente na translucidez da cerâmica. Sendo assim, quanto maior o no de cristais na matriz vítrea, menor a translucência da cerâmica e quanto menos partículas infiltradas, maior a translucência (HELVEY GA, 2014). Como pode ser visto nos Quadros 1 e 2. 
Revista Eletrônica Acervo Saúde / Electronic Journal Collection Health ISSN 2178-2091

Quadro 1 - Características das cerâmicas feldspáticas e reforçadas.

\begin{tabular}{|c|c|c|c|c|c|}
\hline Cerâmica & Sistemas & Indicações & Características & Sensibilidade & $\begin{array}{c}\text { Resistência } \\
\text { flexural (MPa) }\end{array}$ \\
\hline $\begin{array}{c}\text { Feldspáticass } \\
\left(\mathrm{SiO}_{2}-\mathrm{Al}_{2} \mathrm{O}_{3}-\mathrm{Na}_{2} \mathrm{O}-\right. \\
\left.\mathrm{K}_{2} \mathrm{O}\right)\end{array}$ & $\begin{array}{l}\text { VITABLOCKS Mark II, VITA Triluxe } \\
\text { Bloc, VITABLOCS Esthetic Line, } \\
\text { VITAVM7, VITA VM9, VITAVM11, VITA } \\
\text { VM13 (VITA); Duceram Plus, Duceram } \\
\text { Kiss (Degudent); Super-Porcelain EX- } \\
\text { 3, Cerabien (Noritake) }\end{array}$ & $\begin{array}{l}\text { Cobertura de infra-estrutura } \\
\text { metálica (metalocerâmicas) } \\
\text { Inlays, onlays e facetas } \\
\text { Recobrimento de in- } \\
\text { fraestrutura cerâmica (livre de } \\
\text { metal) }\end{array}$ & $\begin{array}{c}\text { Matriz vítrea com } \\
\text { partículas cristalinas } \\
\text { dispersas }\end{array}$ & Ácido sensíveis & $110-150$ \\
\hline $\begin{array}{l}\text { Reforçadas com } \\
\text { leucita } \\
\left(\mathrm{SiO}_{2}-\mathrm{Al}_{2} \mathrm{O}_{3}-\mathrm{K}_{2} \mathrm{O}\right)\end{array}$ & $\begin{array}{c}\text { IPS Empress (Ivoclar Vivadent), } \\
\text { Optimal Pressable Ceramic (Jeneric } \\
\text { Pentron), IPS ProCAD (Ivoclar } \\
\text { Vivadent), IPS Empress Esthetic } \\
\text { (Ivoclar Vivadent), } \\
\text { Paradigm }{ }^{\mathrm{TM}} \mathrm{C}(3 \mathrm{M} / \mathrm{ESPE})\end{array}$ & $\begin{array}{l}\text { Inlays, onlays e facetas } \\
\text { Coroas anteriores } \\
\text { Recobrimento de } \\
\text { infraestrutura cerâmica }\end{array}$ & $\begin{array}{l}\text { Matriz vítrea com } \\
\text { reforço de partículas de } \\
\text { leucita }\end{array}$ & Ácido sensíveis & $97-180$ \\
\hline $\begin{array}{c}\text { Reforçadas com } \\
\text { dissilicato } \\
\text { de lítio e derivados } \\
\left(\mathrm{SiO}_{2}-\mathrm{Li}_{2} \mathrm{O}\right)\end{array}$ & $\begin{array}{c}\text { IPS Empress }{ }^{\circledR} \text { 2, IPS e.max }{ }^{\circledR} \text { Press } \\
\text { (Injetado), IPS e.max }{ }^{\circledR} \text { CAD (fresado), } \\
\text { (Ivoclar Vivadent); 3G }{ }^{\mathrm{TM}} \text { OPC (Pentron } \\
\text { Ceramic Inc.), Obsidian (Glidewell } \\
\text { Laboratories), Suprinity (Vita), Celtra } \\
\text { Duo (Dentsply) }\end{array}$ & $\begin{array}{c}\text { Inlays, onlays, } \\
\text { facetas, Infraestruturas de } \\
\text { coroas totais } \\
\text { Prótese fixa de até } 3 \\
\text { elementos anterior ou } \\
\text { posterior até pré-molares, } \\
\text { lentes de contato, prótese } \\
\text { adesiva anterior }\end{array}$ & $\begin{array}{l}\text { Matriz vítrea com } \\
\text { reforço de partículas de } \\
\text { dissilicato de lítio ou } \\
\text { silicato de lítio }\end{array}$ & Ácido sensíveis & $300-400$ \\
\hline
\end{tabular}

Fonte: Helvey GA, (2014) modificada por Neto JMAS et al., 2019.

REAS/EJCH | Vol.Sup.n.40 | e2416 | DOI: https://doi.org/10.25248/reas.e2416.2020 Página 4 de 10 
Revista Eletrônica Acervo Saúde / Electronic Journal Collection Health ISSN 2178-2091

Quadro 2 - Características das cerâmicas infiltradas e policristalinas (alumina e óxido de zircônia).

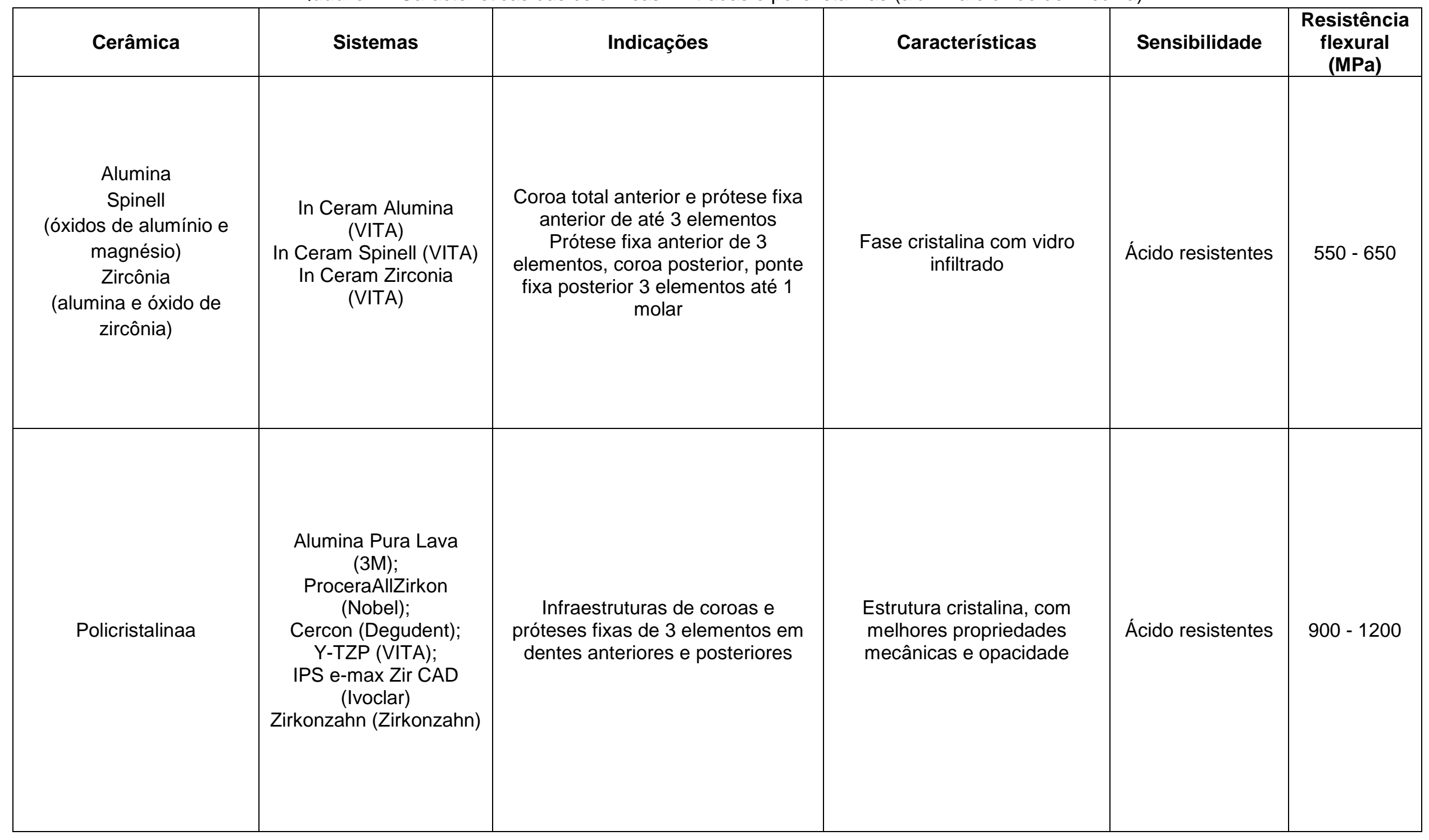

Fonte: Mclaren EA e Figueira J, (2015) modificada por Neto JMAS et al., 2019.

REAS/EJCH | Vol.Sup.n.40 | e2416 | DOI: https://doi.org/10.25248/reas.e2416.2020 Página 5 de 10 


\section{Cerâmicas vítreas (feldspáticas)}

Cerâmicas dentais convencionais têm sua composição à base de sílica $\left(\mathrm{SiO}_{2}\right)$, feldspato de potássio $\left(\mathrm{K}_{2} \mathrm{OAl}_{2} \mathrm{O}_{3} 6 \mathrm{SiO}_{2}\right)$ ou de sódio $\left(\mathrm{Na}_{2} \mathrm{OAl}_{2} \mathrm{O}_{3} 6 \mathrm{SiO}_{2}\right)$, ou ambos, com adição de vidro, opacificadores e pigmentos para controlar a fusão, a temperatura de sinterização, o coeficiente de expansão térmica e a solubilidade. $O$ primeiro sistema usado para peças protéticas a serem utilizadas em alta fusão foram as porcelanas feldspáticas que são materiais compostos por um ou mais vidros e fase cristal as quais se constituíam por feldspato, quartzo e caolim que têm sido desenvolvidas com melhores propriedades desde os anos 80, pois anteriormente eram associados às lâminas de platina, originando as coroas metalocerâmicas (HELVEY GA, 2014).

Cerâmicas feldspáticas, as quais são ácido sensíveis, quando condicionadas com ácido hidrofluorídrico, sofrem dissolução na sua superfície. Ocorre uma condicionamento seletivo da fase vítrea expondo o dióxido de silício $\left(\mathrm{SiO}_{2}\right)$ que promove retenções micromecânicas. Essas rugosidades aumentam a energia de superfície, através das mudanças topográficas mas que precisam se aliar à sinalização e ao uso do cimento resinoso para serem eficazes (CALIXTO R e MASSING N, 2015).

\section{Cerâmicas reforçadas}

Consistem em várias quantidades e tipos de partículas e matriz vítrea, divididos em três principais tipos: reforçadas com leucita, reforçadas com dissilicato de lítio e silicato de lítio reforçada com zircônia. (SHRIVASTAVA S, et al., 2014). Diferem das feldspáticas devido à presença de conteúdo cristalino adicionado ao vidro (dióxido de silício, óxido de potássio, óxido de sódio e óxido de alumínio), na forma de fabricação pois são disponibilizados sob a forma de blocos para fresagem. Podem conter de baixa à moderada quantidade de leucita. Se comportam como vidro e necessitam de adesão (DINATO JC, et al., 2014). Cimentada com óxido de zinco, que não tem adesão à coroa de porcelana e, apesar de serem um avanço, seu uso estava restrito a próteses unitárias e coroas e, são contraindicadas para regiões posteriores. (CALIXTO R e MASSING N, 2015).

\section{Leucita}

Leucita foi o primeiro e provavelmente o mais popular reforço com cristais nas cerâmicas. Introduzida no mercado em 1990, com indicação para coroas anteriores e premolares, inlays, onlays e facetas laminadas, utiliza o método de cera perdida. A incorporação de leucita, dentre outras substâncias, melhorou a resistência flexural das cerâmicas, em relação às feldspáticas entre 35 e 55\%. Agem como defletores de cracks, já que durante o processo de sinterização das cerâmicas, as microporosidades que são formadas iniciam os cracks e os propagam levando às falhas (CALIXTO R e MASSING N, 2015). Maior quantidade de leucita leva a um aumento do módulo de ruptura, força compressiva e alto coeficiente de contração térmica. Devido à grande contração térmica, quando resfriada, gera incompatibilidade entre leucita e matriz vítrea resultando em stress compressivo tangencial no vidro, em torno dos cristais que pode agir como defletor de cracks e contribuem com o aumento da resistência da fase fraca (vítrea). (HELVEY GA, 2014).

\section{Dissilicato de lítio e derivados}

São restaurações monocromáticas, recomendadas quando necessita-se de média ou alta translucência, que podem ser caracterizadas à forma desejada e produzem estética comparada às da técnica de camadas. Restaurações cerâmicas de dissilicato de lítio podem ser confeccionadas através da técnica injetada ou cera perdida (enceramento incluído no revestimento, cera evapora e é substituída por injeção por material cerâmico) e fresada (usinada em estágio intermediário de dureza, com coloração azulada, podendo realizar desgastes rápidos e ajustar material manualmente, precisando de forno especial para cristalizar material após usinagem do bloco (DINATO JC, et al., 2014).Indicadas quando há perda severa de estrutura dental, podendo melhorar a resistência à fratura e proteger a estrutura dental. Têm indicações para coroas totais anteriores e posteriores, laminados cerâmicos e fragmentos cerâmicos. Infraestruturas, copings, prótese parcial fixa de até 3 elementos na região anterior, e até segundo premolar. (SILVA W, et al., 2015).

\section{Cerâmica de silicato de lítio reforçado por zircônia}

Cerâmica de vidro de silicato de lítio reforçada com dióxido de zircônio reforçada com $10 \%$ de cristais de zircônia. Desenvolvida para o sistema CAD/CAM, que são a VITA Suprinity ${ }^{\circledR}$ (VITA Zahnfabrik) e CELTRA ${ }^{\mathrm{TM}}$ 
Duo (Dentsply) essa cerâmica apresenta melhoras nas propriedades mecânicas dada pela presença do dióxido de zircônio, sem perder as propriedades ópticas da fase vítrea do silicato de lítio. Por possuírem predominantemente uma matriz vítrea, são sensíveis ao condicionamento ácido, melhorando o processo de adesão. Sua indicação abrange tanta região posterior, quanto áreas estéticas, sendo utilizadas para inlays, onlays, coroas parciais, facetas, coroas na área anterior e posterior (SKRIPNIK NN, 2016).

\section{Infiltradas por vidro}

Criadas para melhorar propriedades mecânicas como a resistência à fratura. Por alumina (In Ceram

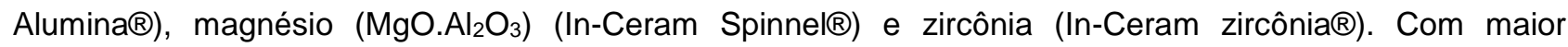
resistência que as cerâmicas vítreas, os óxidos cerâmicos (alumina e zircônia) (In Ceram ${ }^{\circledR}$ Alumina (Vita Zahnfabrik) e Procera All Ceram ${ }^{\circledR}$ (Nobel Biocare) também apresentam resistência flexural maior (650Mpa) contra 400Mpa das vítreas. Principais componentes; $\mathrm{SiO}_{2}$ com pequena adição de cristais de $\mathrm{Al}_{2} \mathrm{O}_{3}, \mathrm{MgO}$, $\mathrm{ZrO}_{2}$ e outros óxidos (ANUSAVICE KJ et al., 2013).

$\mathrm{Na}$ infiltração por vidro, uma fina camada de pasta fluida de partículas de alumínio, silicato de magnésiaalumina (Spinell) ou zircônia é inserida num troquel refratário seco, onde a água desta fina camada é drenada e a camada é sintetizada no troquel, sendo então coberta por uma fina camada da fase vítrea. Durante a queima, o vidro fundido infiltra nos poros interconectados do núcleo cerâmico. Camadas de porcelana translúcida de cobertura, são queimadas sobre o núcleo cerâmico para promover contorno e coloração final (DINATO JC, et al., 2014).

\section{Alumina infiltrada por vidro}

Todas as cerâmicas contêm estruturas refratárias formadas por partículas de óxido de Alumínio sob a forma de alumina (caolim) e dióxido de silício sob a forma de sílica. A opacidade do caolim deve-se à sua quantidade sob a forma cristalina no corpo da cerâmica, sendo a opacidade, resultante também da refração da alumina. Devido a esse problema permaneceu por muito tempo, iniciou-se a formulação de porcelanas feldspáticas com cada vez menos caolim, até que ele foi retirado completamente da composição das cerâmicas em 1938. Com a remoção do caolim, a resistência do vidro diminuiu e somente a adição do quartzo não melhorou a resistência, melhorou apenas a estética (BISPO LB, 2015).

Em meados de 1960 surgiram as primeiras cerâmicas reforçadas, desenvolvidas por McLean e Hughes (HELVEY GA, 2014). São cerâmicas formadas por uma estrutura porosa de alumina, a qual é mecanicamente frágil, infiltrada com vidro de baixa viscosidade. A diferença de sua composição com relação à convencional é a presença inicialmente de 40 a $50 \%$ de óxido de alumínio $\left(\mathrm{Al}_{2} \mathrm{O}_{3}\right)$ em pó conferindo uma resistência de (120/180 Mpa), e posteriormente aperfeiçoada para $85 \%$ e menos de $5 \%$ de sílica, limitando a adesão quando tratada por métodos tradicionais como: ácido fluorídrico ou com óxido de alumínio, aumentando assim a força e dureza das cerâmicas, já que a alumina aumenta a força mais que a leucita e melhora a resistência à fratura (CHUN EP, et al., 2017).

\section{Magnésio infiltrada por vidro}

As cerâmicas In Ceram Spinell $($ Vita) foram introduzidas em 1994, para superar a opacidade da In Ceram Alumina $\AA^{\circledR}$. São compostas por alumina e magnésio $\left(\mathrm{MgAl}_{2} \mathrm{O}_{4}\right.$ - aluminato de magnésio), apresentam semelhança com a In Ceram Alumina ${ }^{\circledR}$ no processo de confecção, divergindo na composição, originando assim um material mais translúcido que as cerâmicas à base de alumina e zircônia infiltradas por vidro, já que tanto o aluminato de magnésio como a matriz vítrea apresentam baixo índice de refração. Apresentam também uma resistência flexural cerca de $25 \%$ inferior à da alumina (280 a $380 \mathrm{Mpa}$ ) com indicação para coroas anteriores, inlays, onlays e facetas (VARGAS MA, 2011).

\section{Zircônia infiltrada por vidro}

Considerada como modificação do sistema InCeram Alumina $\AA^{\text {a a }}$ InCeram Zircônia $\AA^{\circledR}$ teve adição de cerca de $69 \%$ de óxido de alumina $\left(\mathrm{Al}_{2} \mathrm{O}_{3}\right)$ e $31 \%$ de óxido de zircônio $\left(\mathrm{ZrO}_{2}\right)$. É considerada a mais resistente dentre esses três tipos (InCeram Alumina, InCeram Spinell, InCeram Zirconia) com resistência flexural entre 600 e $700 \mathrm{Mpa}$. Apesar de resistentes, não podem ser usados em áreas estéticas. Devido à sua alta tenacidade à fratura, ela é de grande importância na Odontologia, porém, como não existe zircônia pura na natureza, recebe do nome de dióxido de zircônia. Largamente usado em medicina e odontologia devido à força 
mecânica e estabilidade dimensional e módulo de elasticidade semelhante ao aço inoxidável (Mattei FP e Alexandre MC, 2011).

É capaz de parar o crack gerado pelo stress de tensão induzido pela mudança da configuração tetragonal para monoclínica gerando aumento do volume que resulta na mudança de stress de tensão para stress de compressão em torno da ponta do crack. Porém essa transformação de fase tetragonal-monoclínica também favorece para que ocorra degradação da superfície da zircônia por envelhecimento a baixas temperaturas, diminuindo assim suas propriedades mecânicas. São ácido-resistentes, ou seja, não sofrem condicionamento com ácido fluorídrico e não possuem adesão química, tendo pouca indicação nos preparos em que existem poucas retenções no substrato dental (NAUTIYAL A, et al., 2015).

\section{Cerâmicas policristalinas}

Não contêm vidro em sua composição. Átomos são inseridos e dispostos num arranjo regular cristalino, aumentando a resistência e diminuindo a propagação de cracks apresentando elementos e partículas que alteram as propriedades ópticas, apresentando maior resistência e tenacidade, diminuindo assim riscos de fratura e a estética. Possuem resistência à fratura bem superior que as cerâmicas vítreas, devido à diminuição da fase vítrea das mesmas e aumento do conteúdo cristalino. Podem ser a primeira opção em regiões onde há altas cargas mastigatórias, como na região posterior (GRACIS S, et al., 2015).

\section{Zircônia}

Zircônia é uma cerâmica cristalina, biocompatível com tecidos dentários, que permite uma integração natural entre dentes e gengiva, não é alérgena e também não confere alteração de paladar. É o 18ํe elemento mais abundante na crosta terrestre, existindo em estado puro sob a forma amorfa (pó negro azulado) e cristalina (metal branco e dúctil). Inicialmente usado na Odontologia para coroas protéticas e atualmente indicados para reconstrução protética (GRACIS S, et al., 2015).

É um material polimórfico que apresenta três fases que variam de acordo com a temperatura de fusão: são monoclínicas quando sua temperatura varia da ambiente até $1700^{\circ} \mathrm{C}$, tetragonal, quando sua temperatura varia entre $1700^{\circ} \mathrm{C}$ e $2370^{\circ} \mathrm{C}$ e, acima disso se classificam como cúbicas. Quando se transforma da forma monoclínica para tetragonal, seu volume aumenta em $4 \%$, fazendo com que os cracks sejam fechados aumentando a resistência à fratura do material, necessita então ser estabilizada na forma tetragonal ou cúbica, com a adição de partículas de óxido de ítrio. Que atuam como estabilizadores, fazendo com que a zircônia estabilizada por ítrio Y-TZP ofereça resistência mecânica, já que resistem à propagação dos cracks (CONRAD HJ, et al., 2007).

Os tipos de cerâmicas e materiais cerâmicos que surgiram na última década, aumentaram significativamente a gama de materiais disponíveis no mercado. As classificações das cerâmicas odontológicas têm ajudado aos técnicos e profissionais da odontologia na escolha do material cerâmico ideal para cada caso a partir de informações obtidas através de composição, características químicas e mecânicas, indicações dos materiais, critérios observados a partir de informações de dureza, resistência flexural e estética (KRISHNA JV, et al., 2009). Outra forma importante de classificar o sistema cerâmico é de acordo com a sensibilidade ao ácido hidrofluorídrico, podendo serem classificadas em cerâmicas ácido resistentes e ácido sensíveis, estabelecendo um elo entre a sua composição e características mecânicas e indicações, além da técnica de cimentação (VENTURINI AB, et al., 2015).

As cerâmicas feldspáticas ou reforçadas com leucita e dissilicato de lítio, (vítreas) são sensíveis à ação do ácido hidrofluorídrico, podendo ser cimentada pela técnica adesiva pois possuem alto conteúdo vítreo, o que as tornam altamente estética. (VENTURINI AB, et al., 2015).

A união adesiva quando se utiliza ácido hidrofluorídrico nas concentrações de 3\%, $5 \%$ e $10 \%$ é semelhante e estável, porém que maiores concentrações do ácido causam maior alteração topográfica na superfície das cerâmicas feldspáticas, gerando menor ângulo de contato, (KRISHNA JV, et al., 2009). Estudos in vitro a respeito do tempo de aplicação de ácido hidrofluorídrico de 0,20,60,120 e 180 segundo, sobre as cerâmicas de dissilicato de lítio, geram maior rugosidade superficial na mesma e menor resistência flexural, devendo o tempo limite para cerâmicas de dissilicato de lítio, ser de 20 segundos pois o mesmo aumenta a união adesiva e diminui a perda da resistência flexural (DINATO JC, et al., 2014). 
$\mathrm{Na}$ avaliação do padrão de fratura e carga para fratura, em cerâmicas de alumina, zircônia e cerâmicas vítreas, em coroas de incisivos, foi observado que a zircônia é a mais resistente, suportando maior carga e que apesar da cerâmica vítrea ser mais fraca que a de alumina, não houve diferença significativa no resultado. (ANUSAVICE KJ et al., 2013). A zircônia, devido à sua resistência mecânica aumentada, esta cerâmica tem maior indicação para confeccionar abutments que a alumina. Devendo porém serem respeitados seus princípios físicos, mecânicos e técnicos, planejando-se conectores com no mínimo $4 \mathrm{~mm}$ de espessura (CALIXTO R e MASSING N, 2015).

A disponibilização no mercado de sistemas cerâmicos com melhores propriedades de resistência (tração e flexural), tenacidade, translucidez e com capacidade de suprir necessidades estéticas e funcionais das cerâmicas utilizadas nas reabilitações, aumenta a necessidade e importância do profissional ter conhecimento a respeito da diversidade desses materiais disponíveis no mercado para indica-lo de acordo coma melhor necessidade clínica e obter resultados duradouros com tempo de vida clínico aumentado (Mattei FP e Alexandre MC, 2011).

\section{CONSIDERAÇÕES FINAIS}

Selecionar adequadamente a cerâmica baseada apenas na sua translucência pode levar a uma indicação errônea, podendo dessa forma, confundir o profissional. Então, para facilitar a seleção do material, as cerâmicas podem ser classificadas em dois grupos principais, os quais se baseiam na presença ou ausência de vidro na composição do material, sendo eles: cerâmicas vítreas e cerâmicas policristalinas. Algumas etapas a serem seguidas durante o processo de reabilitação protética com cerâmicas: planejamento adequado do caso, preparo conservador, preservando o máximo de esmalte, eleição adequada de cerâmicas para uso, seleção apropriada dos materiais e métodos de cimentação e planejamento adequado para a manutenção das restaurações. A busca pela excelência estética na Odontologia, se mostra na diversidade e quantidade de sistema cerâmicos disponibilizados no mercado, cada um com suas vantagens e desvantagens, indicações e contraindicações, cabendo ao cirurgião-dentista avaliar a real indicação de cada sistema cerâmico.

\section{REFERÊNCIAS}

1. ANUSAVICE KJ, et al. Materiais dentários, 12ed, Elsevier, Rio de Janeiro, 2013; p. 619.

2. BISPO LB. Cerâmicas odontológicas: vantagens e limitações da zircônia. Rev Bras.Odontol. v. 76, n 1⁄2, 2015; p. 24 29.

3. CALIXTO R, MASSING N. Longevidade das restaurações cerâmicas anteriores. Parte 1, Rev. Dental Press Estética, Araraquara, 2015; p. 18-28.

4. CALIXTO R, MASSING N. Longevidade das restaurações cerâmicas anteriores. Rev. Dental Press Estética. São Paulo. 2015; p. 18-28.

5. CHUN EP, et al. Microstructural analysis and reliability of monolithic zircônia after simulated adjustement protocols, Dent Mater. 2017.

6. CONRAD HJ, et al. Current ceramic Materials and Systems with Clinical Recommendations: A systematic review, J. Prosthet Dent. 2007; p.389.

7. DINATO JC, et al. Sistema CAD/CAM - substituindo o processo de cera perdida na prática clínica com maior precisão, resistência e menor custo, ProteseNews, 2014; p.22-36.

8. DINATO JC, et al. Sistema CAD/CAM - substituindo o processo de cera perdida na prática clínica com maior precisão, resistência e menor custo, Protese News. 2014; p. 22-36.

9. FERREIRA HA, et al. influência de agentes clareadores nas propriedades superficiais (rugosidade e microdureza) de uma cerâmica odontológica, cerâmica. 2016; P. 55-59.

10. GARCIA LFR, et al. Análise crítica do histórico e desenvolvimento das cerâmicas odontológicas, Rev. Gaúcha Odontol. São Paulo. 2011; p. 67-73.

11. GRACIS S, et al. A New Classification System for All-Ceramic and Ceramic-like Restorative Materials, The Int J Prosthod. 2015; p.227-235.

12. HELVEY GA. Classifying Dental Ceramics: Numerous Materials and Formulations Available for Indirect Restorations, Compendium. 2014; p.38-43

13. KELLY JR, et al. Ceramic materials in dentistry: historical evolution and current practice, Australian Dental Journal, $2011 ;$ p. 84.

14. KRISHNA JV, et al. Evolution of metal-free ceramics, The Journal of Indian Prosthodontic Society, India, v.9, 2009; p. 70-75. 
15. KRISHNA JV, et al. Evolution of metal-free ceramics, The Journal of Indian Prosthodontic Society, 2009; P. 70-75.

16. MAGNO P, BELSER U. Restaurações adesivas de porcelana na dentição anterior- Uma abordagem biomimética, $1^{a}$ ed. Quintessense Editora Ltda., São Paulo, 2012; p.406.

17. MATTEI FP, ALEXANDRE MC. Chain, Estado da arte das cerâmicas odontológicas. FULL Dentristry in Science, 2011; p. 84-91.

18. MCLAREN EA, FIGUEIRA J. Updating classifications of ceramic dental materials: a guide to material selection. Inside Dentistry. 2015; p. 48-72.

19. MCLAREN EA, FIGUEIRA J. Updating Classifications of Ceramic Dental Materials: A Guide to Material Selection, Compendium, 2015; p.400-406.

20. NAUTIYAL A, et al. Recent ceramic materials: an esthetic promise to patient, The Journal of Indian Prosthodontic Society.2015 p.26-30.

21. SHRIVASTAVA S, et al. Ceramic cementation: a key to succesfull restoration, Annals and Essences of Dentistry. Department of Prosthodontics, Crown Bridge and Implantology. India, 2014; p. 35-43.

22. SILVA W, et al. Restabelecimento estético e funcional multidisciplinar, Full Dent. Sci. 2015; P. 210-219.

23. SKRIPNIK NN. Cerâmicas para facetas em dentes anteriores: uma revisão de literatura, TCC UFSC, 2016; P. 36p.

24. VARGAS MA. Cementing all-ceramic restorations, JADA, 2011; p. 205-245

25. VENTURINI AB, et al. Effect of Hydrofluoric Acid Concentration on Resin Adhesion to a Feldspathic Ceramic, J Adhes Dent. 2015; p. 313-320. 